\title{
IDENTIFIKASI AKUIFER BAWAH AIR DENGAN KONFIGURASI SCHLUMBERGER MENGGUNAKAN RESISTIVITY METER BERBASIS BOOST CONVERTER DI UNIVERSITAS BORNEO TARAKAN
}

\section{IDENTIFICATION OF UNDERWATER AQUIFER WITH SCHLUMBERGER CONFIGURATION USING RESISTIVITY METER BASED ON BOOST CONVERTER ON BORNEO TARAKAN UNIVERSITY}

\author{
Abdul Muis Prasetia 1), Eko Prihartanto ${ }^{2)}$, Rahmat Faizal ${ }^{3)}$ \\ 1) Teknik Elektro, Fakultas Teknik \\ 2),3) Teknik Sipil, Fakultas Teknik \\ Universitas Borneo Tarakan \\ Jalan Amal Lama Nomor 1, Tarakan \\ Email: ${ }^{1}$ prasetia.electric@borneo.ac.id
}

\begin{abstract}
ABSTRAK
Air merupakan salah satu elemen utama kehidupan makhluk hidup, sehingga semua mahluk hidup sangat memerlukan air. Untuk mencukupi kebutuhan air bersih pada masyarakat dapat menggunakan air hujan, air tanah dan lain-lain, penggunaan sumber air tanah perlu diketahui potensi jumlah maupun mutunya. Penyebaran air tanah dideskripsikan secara vertikal dan horizontal, deskripsi air secara horizontal dapat dilihat melalui penyebaran formasi geologi yang bertindak sebagai akuifer. Untuk mendapatkan kondisi hidrogeologi dan geologi perlu dilakukan kajian dengan menggunakan metode geolistrik melalui resistivity meter. Berdasarkan latar belakang tersebut, peneliti menerapkan keunggulan boost converter pada desain resistivity meter yang diusulkan. Konfigurasi Elektroda yang diterapkan dalam penelitian ini menggunakan metode Schlumberger dengan parameter yang terukur ialah arus listrik (I), beda potensial (V) dan spasi elektroda, sedangkan parameter yang dihitung adalah tahanan jenis $(\rho)$. Data hasil pengukuran diolah untuk didapatkan penampang model resistivity 1 dimensi (1D) bawah permukaan. Berdasarkan hasil eksplorasi geolistrik dan perhitunganperhitungannya menunjukkan keberadaan akuifer air tanah pada kedalaman 6.54 -56.67 m dengan tahanan jenis $36.98 \Omega \mathrm{m}$ dan perkiraan litologi adalah pasir.
\end{abstract}

Kata Kunci : Akuifer, Schlumberger, Resistivity Meter, Boost Converter

\begin{abstract}
Water is one of the main elements of living things, so that all living things really need water. To meet the needs of clean water, the community can use rainwater, ground water and others, the use of groundwater resources need to recognize the potential quantity and quality. The spread of groundwater is described vertically and horizontally, horizontal description of water can be seen through the spread of geological formations that act as aquifers To obtain hydrogeological and geological conditions, it is necessary to do a study using the geoelectric method through a resistivity meter. Based on this background, researchers applied the benefit of a boost converter in the design of the proposed resistivity meter. The Electrode Configuration applied in this study using the Schlumberger method with measured parameters is electric current (I), potential difference (V) and electrode spacing, while the calculated parameter is type $(\rho)$ resistance. Measurement data is processed to obtain a cross section of 1-dimensional resistivity model (1D) below the surface. Based on the results of geoelectric exploration and its calculations show the presence of groundwater aquifers at a depth of $6.54-56.67 \mathrm{~m}$ with resistances of $36.98 \Omega \mathrm{m}$ and estimates of lithology are sand.
\end{abstract}

Keywords: Aquifer, Schlumberger, Resistivity Meter, Boost Converter 


\section{PENDAHULUAN}

Air merupakan kebutuhan utama bagi manusia, tumbuhan dan hewan, artinya semua mahluk hidup sangat memerlukan air. Kebutuhan air bersih bagi manusia untuk kehidupan sehari-hari, seperti mandi, mencuci, memasak dan lain-lain volumenya semakin meningkat. Kebutuhan air bersih suatu daerah semakin tinggi seiring dengan peningkatan jumlah warga dan kegiatan pembangunan. Petingnya memperhatikan sumber air bersih menjadi prioritas utama untuk menjaga kondisi sosial, ekonomi dan keamanan. Kota Tarakan adalah kepulauan di tengah lautan yang menjadikan kota penghasil migas ini harus berupaya keras untuk mencukupi kebutuhan air bersih, karena Kota Tarakan sangat bergantung dengan turunnya air hujan sebagai sumber utama air bersih dengan curah hujan tidak pasti (tarakan.go.id, 2015).

Untuk mencukupi kebutuhan air bersih pada masyarakat dapat menggunakan air hujan, air tanah dan lain-lian, penggunaan sumber air tanah perlu diketahui potensi jumlah maupun mutunya. Air tanah merupakan air berada di bawah permukaan yang memiliki kedalaman beberapa meter bahkan puluhan hingga ratusan meter. Umumnya air tanah yang berada pada lapisan yang paling dalam biasanya memiliki mutu air baik, seperti jernih, tidak berbau dan tidak asam. Hal ini karena air tanah tersebut telah mengalami proses penyaringan yang cukup tebal oleh lapisan batuan bawah permukaan (Supriyanto, 2015).

Penyebaran air tanah terdeskripsikan secara horizontal dan vertical, deskripsi air secara horizontal dapat dilihat melalui penyebaran formasi geologi yang bertindak sebagai akuifer. Akuifer merupakan lapisan batuan yang dapat berfungsi sebagai pembawa air atau batuan yang mempunyai struktur butiran sedemikian rupa sehingga dapat mengalirkan air. Sebaliknya lapisan kedap air atau akuiclud adalah batuan yang dapat menyimpan air tanah tetapi tidak dapat mengalirkan dalam jumlah yang berarti. Kondisi bagian akuifer dipengaruhi oleh sifat batuan terutama tingkat porositas dan tingkat permeabilitas (Supriyadi, 2012).
Berdasarkan kenyataan tersebut, untuk mengetahui kondisi hidrogeologi dan geologi perlu dilakukan kajian studi dengan menerapkan suatu metoda yang dapat mempelajari kondisi lapisan batuan, meliputi sifat dan jenis batuan serta penyebaranya. Salah satu metode yang populer adalah dengan menggunakan metode geolistrik melalui resistivity meter. Dalam survei metode geolistrik akan diperoleh kuat arus, nilai tahanan jenis batuan dan nilai beda potensial. Tahanan jenis batuan diproses melalui olah data lebih lanjut untuk memperoleh nilai tahanan jenis tiap lapisan batuan. Dengan demikian lapisan bawah permukaan tanah dapat digambarkan dengan perbedaan nilai tahanan jenis dari masing-masing lapisan tersebut (Hutagalung, 2013). Hasil pemetaan lapisan bawah bertujuan untuk mengetahui gambaran mengenai penyebaran lapisan batuan serta menginformasikan keberadaan lapisan batuan yang berfungsi sebagai akuifer. Metode ini juga memiliki beberapa kelebihan yaitu bersifat tidak merusak lingkungan (Broto, 2008), pengoperasian mudah dan cepat, biaya murah, dan dapat mengidentifikasi jenis tanah sampai beberapa meter ke dalam permukaan bumi (Gijoh, 2017).

Berdasarkan latar belakang tersebut, peneliti melakukan penelitian dengan menerapkan keunggulan resistivity meter untuk identifikasi lapisan batuan dasar yang berfungsi sebagai akuifer. Metode yang terapkan dalam penelitian ini digunakan untuk pengambilan data pada daerah Universitas Borneo Tarakan. Hasil penelitian ini diperoleh data yang dapat menggambarkan struktur lapisan batuan yang berfungsi sebagai akuifer, sehingga dapat dijadikan acuan untuk meningkatkan jumlah air bersih menggunakan air tanah berdasarkan data geologi dan hidrogeologi dari resistivity meter.

\section{METODE PENELITIAN}

Penelitian ini dilakukan untuk mendeskripsikan lapisan batuan dasar dan posisi kedalaman yang bertindak sebagai akuifer di Universitas Borneo Tarakan melalui keunggulan resistivity meter. Persiapan 
penggunaan alat akan dilakukan di Laboratorium Teknik Elektro Universitas Borneo Tarakan, kemudian alat tersebut digunakan untuk mengidentifikasi lapisan batuan dasar di lingkungan kampus Universitas Borneo Tarakan dengan konfigurasi schlumberger. Parameter yang diukur dalam penelitian ini adalah kuat arus listrik (I) beda potensial (V), dan spasi elektroda, sedangkan parameter yang dihitung yaitu tahanan jenis $(\rho)$. Pengolahan dan interprestasi data hasil pengukuran dilakukan di Laboratorium Teknik Sipil Universitas Borneo Tarakan.

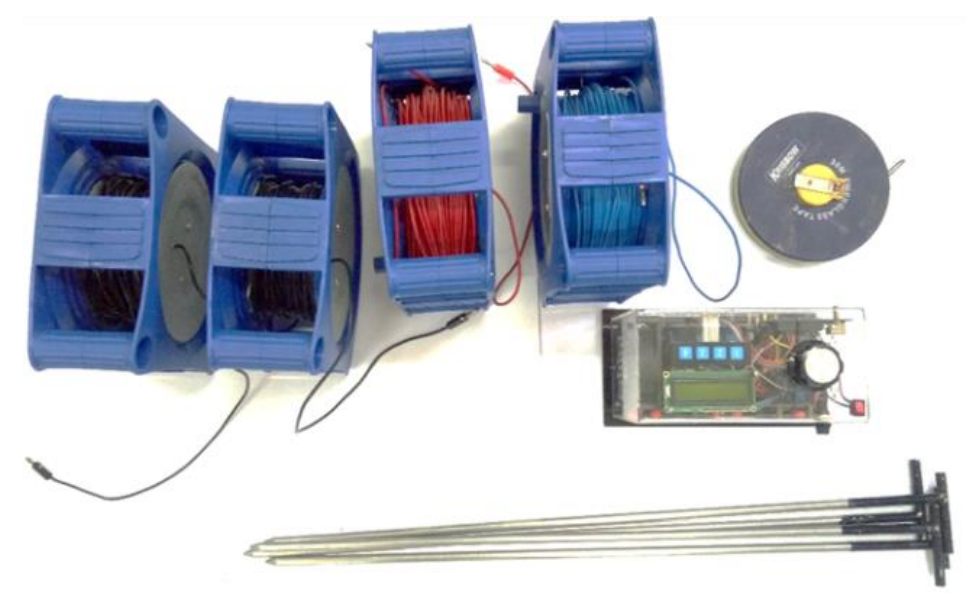

Gambar 1 Resistivity meter berbasis boost converter

\section{Output}

Injeksi

: Terkendali

Catu daya

: 12 Volt

Tegangan keluar

: 800 Volt

Kekuatan

: 75 Watt

Arus ketelitian

: $4 \mathrm{~mA}$

\section{Input}

Voltage

: $2.5 \mathrm{~s} / \mathrm{d} 2000 \mathrm{mV}$

Sistem pembacaan : Digital

Ketelitian Tegangan : $2.5 \mathrm{Mv}$

Penelitian ini dibagi menjadi tiga tahap yaitu, tahap pendahuluan, tahap pengumpulan data, dan tahap analisa.

1. Tahap Pendahuluan

Kajian pustaka yang menjadi dasar keilmuan dalam melakukan penelitian merupakan dasar dari penelitian ini, dalam tahapan ini juga dilakukan analisa awal. Analisa ini dimaksudkan sebagai latar belakang awal
Alat yang digunakan dalam penelitian ini adalah resistivitimeter berbasis boost converter hasil penelitian sebelumnya, dengan elektroda sebanyak empat buah yang mempunyai panjang kabel gulung 200 meter dan 100 meter. Sumber arus yang dipakai adalah arus searah yaitu satu buah baterai $12 \mathrm{~V}$. Peralatan tambahan yang lain yaitu multimeter, kalkulator, lembar tabel data, palu, meteran, dan alat tulis. Berikut ini merupakan spesifikasi resistivity meter yang digubakan. 


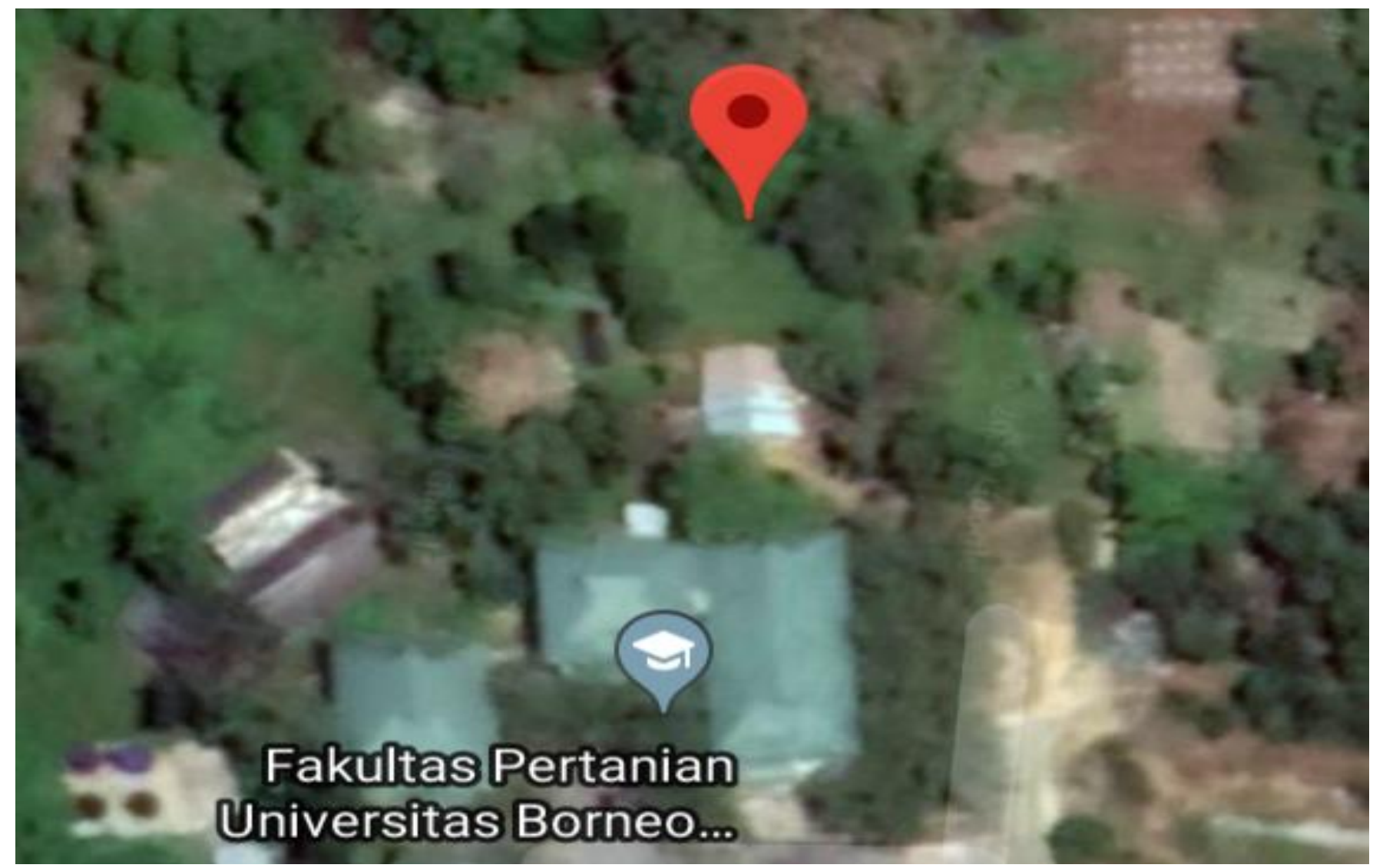

Gambar 2 Lokasi Penelitian

3. Tahap Pengolahan Data

Pengolahan data yang dilakukan dalam menyelesaikan penelitian ini meliputi analisis nilai tahanan jenis (resistivity) semu batuan dengan teknik curve matching dan bantuan perangkat lunak untuk membuat log geolistrik dan mengetahui jenis litologi bawah permukaan. Interprestasi data yang diperoleh dengan cara mengkorelasikan hasil pengolahan data berupa informasi nilai resistivitas dengan nilai kedalaman menggunakan pengetahuan dasar tahanan jenis batuan, data lapisan tanah dari sumur kontrol dan kondisi geologis disekitar daerah tersebut.

\section{HASIL DAN PEMBAHASAN}

Data yang diperoleh dari resistivity meter berbasis boost converter yaitu berupa data resistivitas (V) dan Arus (I). Dari data tersebut kemudian diolah untuk memperoleh tahanan jenis $(\rho)$, kedalaman (h), dan dengan menggunakan software progress didapatkan penampang 1 dimensi dari tiap-tiap lapisan batuan, kemudian hasil keduanya dicocokkan dengan data geologi untuk membantu dalam melakukan interpretasi.

Tabel 1 Data hasil pengukuran

\begin{tabular}{|c|l|l|r|r|}
\hline No & \multicolumn{1}{|c|}{$\mathbf{a}$} & $\mathbf{b}$ & $\mathbf{V ( m V )}$ & $\mathbf{I}(\mathbf{m A})$ \\
\hline 1 & 1 & 0.2 & 68.57 & 18.62 \\
\hline 2 & 1.5 & 0.3 & 66.96 & 18.62 \\
\hline 3 & 2 & 0.3 & 42.92 & 18.62 \\
\hline 4 & 3 & 0.3 & 19.87 & 18.62 \\
\hline 5 & 4 & 0.3 & 28.61 & 43.91 \\
\hline 6 & 5 & 0.3 & 19.31 & 43.91 \\
\hline 7 & 6 & 0.3 & 22.16 & 67.58 \\
\hline
\end{tabular}




\begin{tabular}{|c|l|l|r|r|}
\hline 8 & 6 & 1.2 & 21.43 & 18.62 \\
\hline 9 & 7 & 1.2 & 58.59 & 67.58 \\
\hline 10 & 8 & 1.2 & 45.94 & 67.58 \\
\hline 11 & 10 & 1.2 & 29.27 & 67.58 \\
\hline 12 & 12 & 1.2 & 26.08 & 92.77 \\
\hline 13 & 15 & 1.2 & 32.61 & 215.67 \\
\hline 14 & 20 & 1.2 & 32.24 & 215.67 \\
\hline 15 & 25 & 1.2 & 20.25 & 215.67 \\
\hline 16 & 30 & 1.2 & 12.65 & 215.67 \\
\hline 17 & 30 & 6 & 26.54 & 92.77 \\
\hline 18 & 40 & 6 & 13.94 & 92.77 \\
\hline 19 & 50 & 6 & 22.28 & 215.67 \\
\hline 20 & 60 & 6 & 29.27 & 92.77 \\
\hline 21 & 70 & 6 & 22.44 & 92.77 \\
\hline 22 & 80 & 6 & 17.64 & 92.77 \\
\hline 23 & 90 & 6 & 14.23 & 92.77 \\
\hline 24 & 100 & 20 & 44.42 & 92.77 \\
\hline
\end{tabular}

NIilai k konfigurasi schlumberger dapat dihitung menggunakan persamaan berikut:

$$
k=\frac{\pi}{2 l}\left(L^{2}-l^{2}\right)
$$

dengan $L=A B / 2$ dan $I=M N / 2$. Sedangkan untuk menghitung tahanan jenis $(\rho)$ menggunakan persamaan berikut:

$$
\rho_{a}=k \frac{\Delta V}{I}
$$

Berdasarkan hasil perhitungan dengan bantuan software didapatkan nilai $R, k$, dan $\rho$ seperti terlihat pada tabel berikut.

Tabel 2 Hasil Perhitungan $\mathbf{R}, \mathbf{k}$, dan $\rho$

\begin{tabular}{|c|r|r|r|}
\hline No & \multicolumn{1}{|l|}{$\mathbf{R}$} & \multicolumn{1}{c|}{$\mathbf{k}$} & $\boldsymbol{\rho}$ \\
\hline 1 & 3.683 & 7.536 & 27.752 \\
\hline 2 & 3.596 & 11.304 & 40.651 \\
\hline 3 & 2.305 & 20.462 & 47.167 \\
\hline 4 & 1.067 & 46.629 & 49.759 \\
\hline 5 & 0.652 & 83.262 & 54.250 \\
\hline 6 & 0.440 & 130.362 & 57.329 \\
\hline 7 & 0.328 & 187.929 & 61.623 \\
\hline 8 & 1.151 & 45.216 & 61.623 \\
\hline 9 & 0.867 & 62.224 & 63.882 \\
\hline 10 & 0.680 & 81.849 & 65.887 \\
\hline 11 & 0.433 & 128.949 & 66.135 \\
\hline 12 & 0.281 & 186.516 & 62.091 \\
\hline 13 & 0.151 & 292.491 & 52.370 \\
\hline 14 & 0.149 & 521.449 & 52.370 \\
\hline 15 & 0.094 & 815.824 & 51.463 \\
\hline 16 & 0.059 & 1175.616 & 46.327 \\
\hline 17 & 0.286 & 226.080 & 43.453 \\
\hline 18 & 0.150 & 409.247 & 41.315 \\
\hline 19 & 0.103 & 644.747 & 44.749 \\
\hline 20 & 0.316 & 932.580 & 44.749 \\
\hline 21 & 0.242 & 1272.747 & 46.821 \\
\hline
\end{tabular}




\begin{tabular}{|r|r|r|r|}
\hline 22 & 0.190 & 1665.247 & 48.156 \\
\hline 23 & 0.153 & 2110.080 & 49.224 \\
\hline 24 & 0.479 & 753.600 & 54.877 \\
\hline
\end{tabular}

Data diproses dengan menggunakan matching curve model inversi untuk mendapatkan perkiraan nilai resistivitas antara kurva teori dan kurva lapangan yang paling cocok. Hasil pengolahan titik ukur terlihat pada Tabel 2 dan Gambar 3.

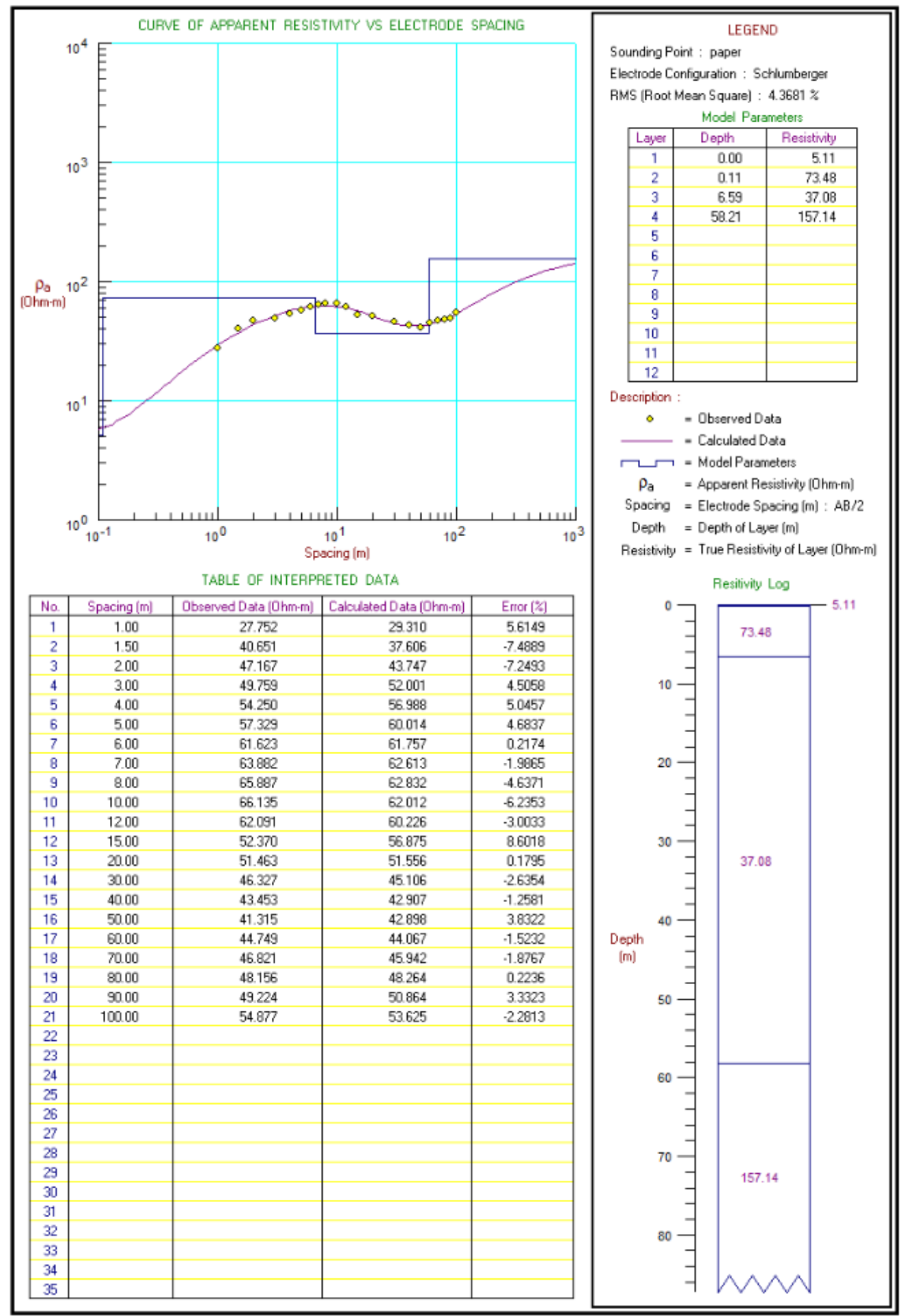

Gambar 3 Hasil Interpretasi data pengukuran 
Hasil interpretasi dari pengolahan data geolistrik pada titik pendugaan berlokasi di Universitas Borneo Tarakan menunjukkan adanya lapisan akuifer. Lapisan akuifer kedalaman 6.54 -56.67 m dengan tahanan jenis $36.98 \Omega \mathrm{m}$. Secara berurutan mempunyai litologi sebagai berikut: lapisan pertama pasir, lapisan kedua batu penutup, lapisan ketiga pasir, dan lapisan terakhir batu pasir atau pasir kuarsa.

\section{KESIMPULAN}

Dari hasil pengolahan data dan pembahasan di atas, maka dapat disimpulkan:

1. Hasil pendugaan geolistrik dapat memperoleh gambaran terkait keadaan lapisan batuan secara vertikal.

2. Keberadaan akuifer air tanah pada kedalaman 6.54 -56.67 m dengan tahanan jenis $36.98 \Omega \mathrm{m}$

3. Didaerah penyidikan mempunyai kondisi hidrogeologi yang bersifat akuifer produktif.

4. Batuan yang bertindak sebagai akuifer di daerah penelitian adalah pasir.

\section{DAFTAR PUSTAKA}

Broto, S., \& Afifah, R. S. (2008). Pengolahan Data Geolistrik Dengan Metode Schlumberger. Jurnal Teknik, 120-128.
Gijoh, O. T., As'ari, \& Pasau, G. (2017). Identifikasi Akuifer Air Tanah Menggunakan Metode Geolistrik Tahanan Jenis Konfigurasi Dipol-Dipol Di Masjid Kampus Universitas Sam Ratulangi. Jurnal MIPA UNSRAT ONLINE 6, 17-20.

Hutagalung, R., \& Bakker, E. (2013). Identifikasi Jenis Batuan Menggunakan Metode Geolistrik Konfigurasi Schlumberger Dalam Perencanaan Pondasi Bangunan di Terminal Transit Desa Passo. Prosiding FMIPA Universitas Pattimura, 159-167.

Supriyadi, Yulianto, A., \& Novianto, T. (2012). Aplikasi Metode Geolistrik Konfigurasi Pole-Pole Untuk Menentukan Sebaran dan Kedalaman Batuan Sedimen di Desa Wonosari Kecamatan Ngaliyan Semarang. Sains dan Teknologi, 90-98.

Supriyanto. (2015). Identifikasi Kedalaman Akuifer Sumur Artesis di Kawasan Kebun Raya UNMUL Samarinda (Krus) Menggunakan Metode Geolistrik Tahanan Jenis Konfigurasi Wenner-Slumberger, Dipole-Dipole dan Pole-Pole. Prosiding Seminar Nasional Sains dan Pendidikan Sains. Samarinda: Universitas Mulawarman Samarinda, 14-18. 